\title{
Disentangling Greenhouse Warming and Aerosol Cooling to Reveal Earth's Climate Sensitivity
}

Authors: T. Storelvmo ${ }^{1 *}$, T. Leirvik ${ }^{2}$, U. Lohmann ${ }^{3}$, P. C. B. Phillips ${ }^{1}$, M. Wild ${ }^{3}$

\author{
${ }^{1}$ Yale University, New Haven, CT, USA. \\ ${ }^{2}$ University of Nordland, Bodø, Norway. \\ ${ }^{3}$ ETH-Zurich, Zurich, Switzerland.
}

Earth's climate sensitivity has long been subject to heated debate and has spurred renewed interest after the latest IPCC assessment report suggested a downward adjustment of its most likely range ${ }^{1}$. Recent observational studies have produced estimates of Transient Climate Sensitivity, i.e. the global mean surface temperature increase at the time of $\mathrm{CO}_{2}$ doubling, as low as $1.3 \mathrm{~K}^{2,3}$, well below the best estimate produced by global climate models (1.8K). Here, we present an observation-based study of the time period 1964 to 2010, which does not rely on climate models. The method incorporates observations of greenhouse gas concentrations, temperature and radiation from approximately 1300 surface sites into an energy balance framework. Statistical methods commonly applied to economic time series are then used to decompose observed temperature trends into components attributable to changes in greenhouse gas concentrations and surface radiation. We find that surface radiation trends, which have been largely explained by changes in atmospheric aerosol loading, caused a cooling that masked approximately one third of the continental warming due to increasing greenhouse gas 
concentrations over the last half-century. In consequence, the method yields a higher transient climate sensitivity $(2.0+/-0.8 \mathrm{~K})$ than other observational studies.

Atmospheric $\mathrm{CO}_{2}$ concentration is projected to double from preindustrial levels during this century ${ }^{1}$, and constraining Earth's temperature response is a primary objective for designing mitigation and adaptation policies. While substantial attention has been devoted to model estimates of Earth's equilibrium climate sensitivity ${ }^{4}$ (i.e., the surface temperature response to $\mathrm{CO}_{2}$ doubling once a new equilibrium climate state has been reached), more relevant to public and policy makers is the temperature change that occurs at the time of $\mathrm{CO}_{2}$ doubling, known as ‘transient climate sensitivity' (TCS) ${ }^{5}$. Constraining TCS based on observational records is complicated by the fact that recent climate change was not forced by $\mathrm{CO}_{2}$ changes alone. Downward solar radiation at the surface (DSRS, measured in $\mathrm{Wm}^{-2}$ ) reported at approximately 1300 surface stations over the time period 1964 -2010 (Fig. 1a and b) display a downward trend in DSRS which is commonly referred to as 'global dimming' (Fig. 1c) ${ }^{6}$. The most plausible explanation for global dimming is increased atmospheric aerosol loading derived from anthropogenic burning of fossil fuels and biomass ${ }^{7}$. The overall effect of aerosols increases Earth's albedo, either by direct interaction with solar radiation, or by increasing the lifetime, areal extent, and/or reflectivity of clouds ${ }^{8}$. For some portions of the world, the appearance of regional trends opposing the global negative DSRS trend ('regional brightening') is observed towards the end of the $20^{\text {th }}$ century, consistent with a reduction in aerosol emissions in much of the developed world ${ }^{6}$. Atmospheric aerosol loading is broadly reflected in global emissions of sulfur dioxide $\left(\mathrm{SO}_{2}\right)$, a precursor for sulfate aerosols (Fig.1c). Sulfate is only one of several aerosol species emitted by human activity, but the relationship between $\mathrm{SO}_{2}$ emissions and 
downward solar radiation broadly reflects the impact of anthropogenic atmospheric aerosol loading on global dimming, and thereafter on the somewhat weaker patterns of regional brightening. Note that trends in volcanic or solar activity also affect DSRS, and that similar $\mathrm{SO}_{2}$ emissions may have different radiative effects depending on factors like latitude and climate regime. Cloudiness also impacts DSRS, but several studies that sought to explain trends in DSRS by changes in cloudiness have concluded that no such relationship could be identified ${ }^{9}$. The fact that a subset of surface stations that can distinguish between clear and cloudy skies show dimming and brightening trends in clear-sky data further points to aerosols as the main driver of DSRS trends ${ }^{6}$.

Perturbations to Earth's radiation budget, whether by greenhouse gases or aerosols, are commonly referred to as radiative forcings $\left(\mathrm{RFs}, \mathrm{Wm}^{-2}\right)$. Positive RFs exerted by anthropogenic $\mathrm{CO}_{2}$ imply a net energy gain by the Earth-atmosphere system and subsequent warming, while negative RFs exerted by anthropogenic aerosols, imply net energy loss. TCS relates the net RF $(\Delta F)$ to the change in global mean temperature $(\Delta T)$ through the following equation:

$T C S=\frac{F_{2 x} \Delta T}{\Delta F}$

where $F_{2 X}$ is the forcing due to a doubling of atmospheric $\mathrm{CO}_{2}$ concentrations. Over the last century, the net forcing has been dominated by the two competing RFs due to long-lived greenhouse gases (GHGs) and aerosols $\left(\Delta F \approx \Delta F_{G H G}+\Delta F_{A E R}\right)^{8}$. For an observed temperature change, an overestimation of $\Delta F$ translates into an underestimation of the TCS (Equation 1), and vice versa ${ }^{10}$. Compared to the RF resulting from GHG increases, the RF associated with aerosol 
forcing is poorly constrained. While tremendous progress has been made on the representation of various aerosol processes in GCMs, aerosol-cloud interactions remain a major source of uncertainty ${ }^{8}$, and the spread in GCM estimates of cloud-mediated and total aerosol effects on climate is almost as wide today as when the field emerged two decades ago ${ }^{11}$. Several studies also suggest that GCMs are generally not able to reproduce the observed global dimming and subsequent regional brightening e.g., ${ }^{7}$. Because of the intimate coupling between the uncertain $\Delta F$ and TCS ${ }^{12}$, estimates of the TCS simulated by GCMs are considered unreliable. TCS estimates that are independent of GCMs are thus critical for advancing the topic.

In this study, we estimate TCS by applying surface air temperature observations from the high-resolution $\left(0.5^{\circ}\right)$ data set from the Climate Research Unit (CRU) ${ }^{13}$, equivalent $\mathrm{CO}_{2}$ concentrations ( $\mathrm{CO}_{2, \mathrm{eq}}$, in ppm, see Methods) from the Annual Greenhouse Gas Index (AGGI) ${ }^{14}$ and DSRS from the Global Energy Balance Archive (GEBA) ${ }^{15}$. Observations from the $~ 1300$ surface stations considered were used to estimate the free parameters of a set of equations predicting temperature at individual stations as a function of $\mathrm{CO}_{2 \text {,eq }}$ and DSRS, using dynamic panel data methods that allow for potential long run cointegrating links among component global time series ${ }^{16}$ (See Methods). Econometric analysis using cointegration methodology has previously been successfully applied to global mean climate time series, in attempts to link observed climate change to anthropogenic and natural climate forcings e.g., ${ }^{17,18}$. The present study goes beyond this body of research by applying dynamic panel modeling methods in conjunction with cointegration techniques to assess individual station responses to long run movements using a rich data set with a spatial as well as temporal dimension, including temperature, $\mathrm{CO}_{2 \text {,eq }}$ and surface radiation. Using this framework, the observed continental temperature evolution from 1964 to 2010 can be reasonably reproduced, and yields a spatially 
averaged temperature increase of approximately 0.8K (Fig. 2). The same analysis applied for zonal bands that contain subsets of the $~ 1300$ surface stations produces consistent results across latitude-bands, but yields a higher sensitivity to $\mathrm{CO}_{2, \text { eq }}$ in the extratropics than at the equator, in alignment with the well-known and expected amplification of greenhouse warming with latitude (see Online-only Methods).

Using the method to calculate temperature evolution under the hypothetical case that $\mathrm{CO}_{2, \mathrm{eq}}$ remained constant at 1964 values results in a cooling that reflects the total aerosol effect. Surface cooling is approximately $0.4 \mathrm{~K}$ averaged over the surface stations considered. Conversely, if DSRS is kept constant at 1964 levels, corresponding to constant atmospheric aerosol concentrations, a warming of $1.2 \mathrm{~K}$ is calculated. In other words, about one third of potential continental warming attributable to increased greenhouse gas concentrations has been masked by aerosol cooling during this time period. The masking effect is strongest before 1990, consistent with previous studies for that time period ${ }^{19}$. An important consequence of this result is that comparable analyses that fail to account for the aerosol masking will erroneously lead to a TCS that is too low by a factor of approximately 2/3. This is consistent with a recent GCM analysis suggesting that aerosol forcing (and forcing associated with other short-lived species) yields a disproportionately larger surface temperature response than $\mathrm{CO}_{2}$ forcing because of the nature and spatial pattern of the forcings ${ }^{20}$. However, note that since the DSRS data set used here provides radiation trends at the surface, as opposed to at the top-of-the-atmosphere where RFs are evaluated, the DSRS change and the resulting cooling found in this study should not be thought of as a traditional forcing-response relationship. 
The analysis further yields a best estimate of the TCS of 3.1K over land, with a 95\% confidence interval of $1.7-4.4 \mathrm{~K}$, which is obtained by computing $\gamma_{3} \log 2$ where $\gamma_{3}$ is the parameter in Equation 3 that controls the sensitivity to $\mathrm{CO}_{2 \text {,eq }}$ (see Methods). We deem this TCS estimate as representative for the global land surface, despite the inhomogeneous spatial coverage of surface stations providing data for the analysis (Fig. 1a); For greenhouse warming, variations with latitude are large and important, whereas variations within a given latitude band are considered of secondary importance. Because the number of surface stations in each latitude band corresponds well with the relative contribution to global land coverage from any given latitude, latitudinal dependence should be well represented (Fig. 1b). Given that land has warmed at exactly double the rate of the ocean over the past century ${ }^{21}$, TCS for the entire globe is estimated to be $\sim 2.0 \mathrm{~K}$ (95\% confidence interval $1.1-2.9 \mathrm{~K}$ ) (obtained by taking TCS $_{\mathrm{Globe}} \approx$ $\operatorname{TCS}_{\text {Land }}\left(\mathrm{f}_{\text {Land }}+0.5 f_{\text {Ocean }}\right)$, where $f_{\text {Ocean }}$ and $\mathrm{f}_{\text {Land }}$ refer to the global land/ocean fractions). A recent analysis used energy budget calculations combined with observations to constrain climate sensitivity ${ }^{2}$, but required GCMs for information on radiative forcings. That study reported a 95\% confidence interval for TCS based on the time period 1970-2009 of 0.7-2.5K, and a best estimate of $1.4 \mathrm{~K}, 0.6 \mathrm{~K}$ lower than the best estimate produced by our GCM-independent method. A comprehensive survey of observational studies of TCS to date yields a wide range, from 0.7 to 3.6K, but generally central estimates below $2 \mathrm{~K}^{18}$. Given that the globe has warmed by approximately $1 \mathrm{~K}$ since pre-industrial times, mainly due to increasing atmospheric $\mathrm{CO}_{2}{ }^{8}$, TCS estimates below 1K appear highly implausible. Incidentally, the present study produces a TCS estimate that is identical to the amount of warming that more than 100 countries have adopted as a limit beyond which severe risks and damage due to global warming are thought to ensue ${ }^{22}$. However, recent arguments have been made for an even lower limit of 'acceptable warming' of 
$1.5 \mathrm{~K}^{23}$. One implication of our findings is that warming will exceed this limit by the middle of the present century without a rapid transition to net zero carbon emission worldwide.

The apparent hiatus in global warming observed over the last decade has been the topic of numerous papers in recent years, and its cause and even existence is currently being debated ${ }^{24,25}$. Some recent estimates of climate sensitivity that incorporate the most up-to-date observational data sets, including the so-called hiatus, have reported very low climate sensitivities ${ }^{3,26}$. To test the sensitivity of our method to the period selected for analysis, we analyzed 25-year subsets of the time period 1964 to 2010, and produced probability density functions (PDFs) for TCS (Fig. 3). Independent of which 25-year time window is selected, the TCS for land lies in the interval 2-4.5K. The PDFs are relatively broad, with high TCSs typically stemming from 25-year periods of rapid warming and lower values during periods with weak temperature trends. Analyses based on shorter time windows are obviously more susceptible to climate variability, and therefore more likely to produce biased trends. Nevertheless, the PDFs peak at a land TCS of 3-4K, increasing the confidence in the best estimate from the full 46-year time period. Thus, the observational-based and GCM-independent analysis presented here supports the best TCS estimate and range produced by GCMs, despite incorporating observations from the so-called hiatus, which has caused other observational methods to produce anomalously low TCS estimates. The temperature evolution predicted by our method does not notably diverge from observations during the hiatus period (1998 - 2010, Fig. 2), suggesting that regions with weak temperature trends also experienced a DSRS decrease during this period, thus hinting at a potential contribution to the hiatus from anthropogenic aerosols trends. However, the current prevailing view is that the hiatus can be attributed to variability internal to the climate system, 
which temporarily causes more heat to mix into the deep ocean via the Equatorial Pacific ${ }^{27}$.

Thus, we suggest that observational studies that produce anomalously low climate sensitivities as a result of incorporating the hiatus period are either overly sensitive to temperature trends of the past decade, or alternatively not properly accounting for the effect of aerosols.

\section{References}

1 Collins, M., R. Knutti, J. Arblaster, J.-L. Dufresne, T. Fichefet, P. Friedlingstein, X. Gao, W.J. Gutowski, T. Johns, G. Krinner, M. Shongwe, C. Tebaldi, A.J. Weaver and M. Wehner. in Climate Change 2013: The Physical Science Basis. Contribution of Working Group I to the Fifth Assessment Report of the Intergovernmental Panel on Climate Change (ed T.F. Stocker, D. Qin, G.-K. Plattner, M. Tignor, S.K. Allen, J. Boschung, A. Nauels, Y. Xia, V. Bex and P.M. Midgley) Ch. 12, 1029-1136 (Cambridge University Press, 2013).

2 Otto, A. et al. Energy budget constraints on climate response. Nat Geosci 6, 415-416, doi:Doi 10.1038/Ngeo1836 (2013).

3 Lewis, N. \& Curry, J. The implications for climate sensitivity of AR5 forcing and heat uptake estimates. Clim Dynam, 1-15, doi:10.1007/s00382-014-2342-y (2014).

$4 \quad$ Allen, M. R. \& Frame, D. J. Call Off the Quest. Science 318, 582-583, doi:Doi 10.1126/Science.1149988 (2007).

5 Padilla, L. E., Vallis, G. K. \& Rowley, C. W. Probabilistic Estimates of Transient Climate Sensitivity Subject to Uncertainty in Forcing and Natural Variability. Journal of Climate 24, 5521-5537, doi:Doi 10.1175/2011jcl13989.1 (2011).

6 Wild, M. Enlightening Global Dimming and Brightening. B Am Meteorol Soc 93, 27-37, doi:Doi 10.1175/Bams-D-11-00074.1 (2012).

$7 \quad$ Wild, M. Global dimming and brightening: A review. J Geophys Res-Atmos 114, doi:Artn D00d16, Doi 10.1029/2008jd011470 (2009).

8 Myhre, G., D. Shindell, F.-M. Bréon, W. Collins, J. Fuglestvedt, J. Huang, D. Koch, J.-F. Lamarque, D. Lee, B. Mendoza, T. Nakajima, A. Robock, G. Stephens, T. Takemura and H. Zhang. in Climate Change 2013: The Physical Science Basis. Contribution of Working Group I to the Fifth Assessment Report of the Intergovernmental Panel on Climate Change (ed T.F. Stocker, D. Qin, G.-K. Plattner, M. Tignor, S.K. Allen, J. Boschung, A. Nauels, Y. Xia, V. Bex and P.M. Midgley) Ch. 8, 659-740 (Cambridge University Press, 2013).

9 Norris, J. R. \& Wild, M. Trends in aerosol radiative effects over Europe inferred from observed cloud cover, solar "dimming" and solar "brightening". J Geophys Res-Atmos 112, doi:Artn D08214, 10.1029/2006jd007794 (2007).

10 Andreae, M. O., Jones, C. D. \& Cox, P. M. Strong present-day aerosol cooling implies a hot future. Nature 435, 1187-1190, doi:10.1038/nature03671 (2005).

11 Lohmann, U. et al. Total aerosol effect: radiative forcing or radiative flux perturbation? Atmos Chem Phys 10, 3235-3246 (2010). 
12 Kiehl, J. T. Twentieth century climate model response and climate sensitivity. Geophys Res Lett 34, doi:Artn L22710, Doi 10.1029/2007gl031383 (2007).

13 Harris, I., Jones, P. D., Osborn, T. J. \& Lister, D. H. Updated high-resolution grids of monthly climatic observations - the CRU TS3.10 Dataset. Int J Climatol 34, 623-642, doi:Doi 10.1002/Joc.3711 (2014).

14 Hofmann, D. J. et al. The role of carbon dioxide in climate forcing from 1979 to 2004: introduction of the Annual Greenhouse Gas Index. Tellus B 58, 614-619, doi:Doi 10.1111/J.1600-0889.2006.00201.X (2006).

15 Gilgen, H. \& Ohmura, A. The Global Energy Balance Archive. B Am Meteorol Soc 80, 831-850, doi:Doi 10.1175/1520-0477(1999)080<0831:Tgeba>2.0.Co;2 (1999).

16 Arellano, M. \& Bond, S. Some Tests of Specification for Panel Data - Monte-Carlo Evidence and an Application to Employment Equations. Rev Econ Stud 58, 277-297, doi:Doi 10.2307/2297968 (1991).

17 Kaufmann, R. K., Kauppi, H., Mann, M. L. \& Stock, J. H. Reconciling anthropogenic climate change with observed temperature 1998-2008. P Natl Acad Sci USA 108, 1179011793, doi:10.1073/pnas.1102467108 (2011).

18 Bindoff, N. L., P.A. Stott, K.M. AchutaRao, M.R. Allen, N. Gillett, D. Gutzler, K. Hansingo, G. Hegerl, Y. Hu, S. Jain, I.I. Mokhov, J. Overland, J. Perlwitz, R. Sebbari and X. Zhang. in Climate Change 2013: The Physical Science Basis. Contribution of Working Group I to the Fifth Assessment Report of the Intergovernmental Panel on Climate Change (ed T.F. Stocker, D. Qin, G.-K. Plattner, M. Tignor, S.K. Allen, J. Boschung, A. Nauels, Y. Xia, V. Bex and P.M. Midgley) Ch. 10, 867-952 (Cambridge University Press, 2013).

19 Wild, M., Ohmura, A. \& Makowski, K. Impact of global dimming and brightening on global warming. Geophys Res Lett 34, doi:Artn L04702, Doi 10.1029/2006gl028031 (2007).

20 Shindell, D. T. Inhomogeneous forcing and transient climate sensitivity. Nature Climate Change 4, 274-277, doi:10.1038/NCLIMATE2136 (2014).

21 Hartmann, D. L., A.M.G. Klein Tank, M. Rusticucci, L.V. Alexander, S. Brönnimann, Y. Charabi, F.J. Dentener, E.J. Dlugokencky, D.R. Easterling, A. Kaplan, B.J. Soden, P.W. Thorne, M. Wild and P.M. Zhai. in Climate Change 2013: The Physical Science Basis. Contribution of Working Group I to the Fifth Assessment Report of the Intergovernmental Panel on Climate Change (ed T.F. Stocker, D. Qin, G.-K. Plattner, M. Tignor, S.K. Allen, J. Boschung, A. Nauels, Y. Xia, V. Bex and P.M. Midgley) Ch. 2, 159-254 (Cambridge University Press, 2013).

22 Meinshausen, M. et al. Greenhouse-gas emission targets for limiting global warming to 2 degrees C. Nature 458, 1158-U1196, doi:Doi 10.1038/Nature08017 (2009).

23 Rogelj, J. et al. Energy system transformations for limiting end-of-century warming to below 1.5 degrees C. Nature Climate Change 5, 519-+ (2015).

24 Meehl, G. A., Arblaster, J. M., Fasullo, J. T., Hu, A. X. \& Trenberth, K. E. Model-based evidence of deep-ocean heat uptake during surface-temperature hiatus periods. Nature Climate Change 1, 360-364, doi:Doi 10.1038/Nclimate1229 (2011).

25 Santer, B. D. et al. Volcanic contribution to decadal changes in tropospheric temperature. Nat Geosci 7, 185-189, doi:Doi 10.1038/Ngeo2098 (2014).

26 Skeie, R. B., Berntsen, T., Aldrin, M., Holden, M. \& Myhre, G. A lower and more constrained estimate of climate sensitivity using updated observations and detailed 
radiative forcing time series. Earth Syst Dynam 5, 139-175, doi:Doi 10.5194/Esd-5-1392014 (2014).

27 Kosaka, Y. \& Xie, S. P. Recent global-warming hiatus tied to equatorial Pacific surface cooling. Nature 501, 403-+, doi:Doi 10.1038/Nature12534 (2013).

\section{Corresponding author}

All correspondence and requests for material should be addressed to Trude Storelvmo

(trude.storelvmo@yale.edu).

\section{Acknowledgements}

This research was supported by an interdisciplinary seed grant awarded by the Yale Climate and Energy Institute (YCEI). PCBP acknowledges research support from the NSF under Grant No. SES 1258258.

\section{Author contributions}

TS and PCBP designed the project. TL performed data quality checks and all technical analysis. MW and UL contributed data and helped with interpretation. TS and PCBP wrote the paper with contributions from all co-authors.

\section{Competing financial interests:}

The authors declare no competing financial interests.

\section{Figure captions}


Figure 1: Radiation measurements from 1300 surface stations. (a) Geographical location of each of the 1300 surface stations incorporated in the study (map courtesy NASA Earth Observatory). (b) Number of surface stations (blue bars, bottom axis) and contribution to global land area, Antarctica excluded (red line, top axis) per $10^{\circ}$ latitude-band. (c) Trend in DSRS, shown as the change relative to 1964, calculated by averaging the year-to-year change over all stations displayed above (right axis, green curve). Also shown are global mean emissions of sulfur dioxide, $\mathrm{SO}_{2}$ (blue curve, left axis, reversed) ${ }^{28,29}$, a precursor to sulfate aerosols. Both curves show 5-year running means.

Figure 2: Temperature trend decomposition. Global land temperature as observed (black curve, CRU TS3.2 data sampled at GEBA stations only, displayed as 5-year running mean), and as predicted with Equations 1 and 2 (green curve). The red curve is calculated using the same framework, but setting $\mathrm{CO}_{2 \text {,eq }}$ concentrations constant at 1964 values, such that the temperature trend is controlled by the DSRS trend alone. Likewise the blue curve shows the temperature predicted with DSRS constant at 1964 values, such that the temperature trend is controlled only by $\mathrm{CO}_{2 \text {,eq. }}$ Predicted temperatures are all shown as 5-year running means. Shadings represent the standard error.

Figure 3: Probably density functions for TCS valid for land. TCS distributions calculated based on 25-year rolling windows: (a) For 25-year periods beginning in 1964-1974, (b) For 25year periods beginning in 1975-1985, (c) For all 25-year periods of the 46-year record. Also shown (d) are the median (horizontal lines), $25^{\text {th }}$ and $75^{\text {th }}$ percentiles (boxes) and 
maximum/minimum values for all distributions (outliers marked with circles). Note that these TCS estimates are valid for land areas only.

\section{Methods}

This study relies on three observational datasets: The Global Energy Balance Archive (GEBA, www.geba.ethz.ch), the Climate Research Unit Time Series (CRU TS, version 3.2, badc.nerc.ac.uk/data/cru/) and the National Oceanic and Atmospheric Administration (NOAA) Annual Greenhouse Gas Index (AGGI, http://www.esrl.noaa.gov/gmd/aggi/) datasets. The latter provides a global and annual mean time series of equivalent $\mathrm{CO}_{2}$ concentrations in the atmosphere, which is calculated by taking the radiative forcings associated with changes in all non- $\mathrm{CO}_{2}$ GHGs and converting them into equivalent changes in atmospheric $\mathrm{CO}_{2}$ (i.e. the $\mathrm{CO}_{2}$ increase required to produce the same forcing). The GEBA dataset reports monthly mean downwelling shortwave radiation (DSRS) reaching the surface, as measured at approximately 2,500 instrumented surface stations worldwide. Out of these, data only from about 1,300 surface stations are selected for the purpose of this study, based on strict criteria on time series length and continuity, as well as data quality control. The availability of high-quality continuous data limited the time period studied here to 1964 - 2010. For each selected station, $i$, the annual mean time series of DSRS, denoted $R_{i}$, is assigned a corresponding high-resolution temperature time series $T_{i}$ from CRU TS3.2. The CRU TS3.2 dataset is available for download from the British Atmospheric Data Center (BADC) and is provided on a $0.5^{\circ} \times 0.5^{\circ}$ horizontal resolution. The third and final dataset, AGGI, provides annual and global mean atmospheric abundances for all major well-mixed long-lived greenhouse gases: carbon dioxide, methane, nitrous oxide, CFC-12 and 
CFC-11, as well as 15 minor halogenated gases from the NOAA global air sampling network. By converting the abundances of all other gases than $\mathrm{CO}_{2}$ into $\mathrm{CO}_{2}$ equivalent abundances, the AGGI data set can offer an annual and global mean time series of equivalent $\mathrm{CO}_{2}$ abundance $\left(\mathrm{CO}_{2, e q}\right)$, which is the time series that is used here. Because these well-mixed GHGs exhibit little spatial variability, the global mean values can be taken as valid for all surface stations ${ }^{8}$. These time series, two of them specific to each of the 1300 surface stations and the third offering one single annual value for the entire globe, are incorporated into Equations 2 and 3 below, which combined predict the temperature evolution at individual surface sites ${ }^{30}$.

The equations (originally derived in ref. 28) thus describe the annual mean temperature at any given station in year $t+1$ as a function of local and global mean temperatures $\left(T_{i}\right.$ and $\left.T\right)$, local and global mean DSRS, as well as the global mean $\mathrm{CO}_{2, \mathrm{eq}}$, all for the previous year $t$. The dependence of local temperature evolution on these variables is justified based on energy balance considerations, but note that we are not explicitly solving an energy balance model here. Instead, the energy balance framework is simply used to identify variables that might be expected to exert an influence on local temperature evolution . Thereafter, the parameters that relate local temperature evolution to these variables are determined entirely by our observed time series, using the following equations:

$$
\begin{aligned}
& T_{i, t+1}=\beta_{1} T_{i, t}+\beta_{2} R_{i, t}+\lambda_{t}+u_{i, t+1} \\
& \lambda_{t}=\gamma_{0}+\gamma_{1} T_{t}+\gamma_{2} R_{t}+\gamma_{3} \log \left(C O_{2, e q}\right)
\end{aligned}
$$


where $\beta_{1}, \beta_{2}, \gamma_{0}, \gamma_{1}, \gamma_{2}$ and $\gamma_{3}$ are parameters that are constrained by the 3-dimentional datasets and $u_{i, t+1}$ is a station-specific idiosyncratic shock. Estimation is performed using dynamic panel data and cointegration methods. The goal is to estimate the parameter values (the $\beta^{\prime} s$ and $\gamma^{\prime} s$ ) that best describe all observations over time and space in a predictive framework (for $T_{i, t+1}$ ), allowing for local transient responses (via $\left.\beta_{1} T_{i, t}\right)$ to long-run global influences $\left(\lambda_{t}\right)$ and the presence of stochastic trends in those global forcing factors. Time series nonstationarity and comovement among the global variable constituents of $\lambda_{t}$ is accommodated through the predictive regression form of Equation 2 and the use of cointegrating regression and error correction techniques that allow for nonstationarity in the global drivers. In particular, when $T_{t}, R_{t}$, and $\mathrm{CO}_{2, e q}$ are cointegrated, the time series effect $\lambda_{t}$ may be interpreted as a long run equilibrium global forcing effect that acts as one of the drivers in Equation 2. Table 1 shows the parameter values that result from the direct application of dynamic panel methods. Further econometric analysis and discussion is provided in the online-only Methods section and Supplementary Tables S1-S5. Note that this approach implicitly assumes that there is no long-term trend in Earth's heat capacity, which is dominated by ocean heat uptake.

As expected, at any year the present temperature will be a relatively good predictor of next year's temperature (parameter $\beta_{1}$ ). The temperature influence of the local DSRS is evident by the fact that $\beta_{2}$ is positive and significantly different from zero - the more incoming solar radiation at the surface, the warmer. The parameter that relates local temperature in year $t+1$ to the station mean temperature in year $t\left(\gamma_{1}\right)$ represents two processes; transport of heat to/from the stations from/to the surroundings, as well as the Planck feedback (a warmer land surface loses more energy to space through infrared radiation). The observations suggest that the latter dominates. The parameter relating local temperature to global (that is, station-mean) DSRS ( $\left.\gamma_{2}\right)$ is not 
significantly different from zero, and the observations therefore suggest that the global solar radiation balance does not have a strong influence on local temperature trends. An alternative interpretation is that a significant proportion of the DSRS trend is due to atmospheric black carbon (BC) aerosols. Because of the positive forcing that $\mathrm{BC}$ exerts at the top of the atmosphere, an associated warming would in this case be expected outside major source regions. However, since the impact of the global radiation trend on local temperature is not statistically significant, this could be indicative of a combination of sulfate and BC, which causes temperature perturbations due to non-local radiation trends to be small. Finally, $\mathrm{CO}_{2 \text {,eq }}$ has a strong impact on local temperatures, as evident by the positive $\gamma_{3}$ which is significantly different from zero. The value of $\gamma_{3}$ allows for calculations of the TCS through Equation 2 and 3 . The equations yield the temperature response to a doubling of $\mathrm{CO}_{2, \mathrm{eq}}$, for example over the preindustrial value of 280ppm, as follows: $\Delta \mathrm{T}_{2 \times \mathrm{CO} 2}=\gamma_{3} \log (560)-\gamma_{3} \log (280)=\gamma_{3} \log (560 / 280)=$ $\gamma_{3} \log 2$.

Code availability: The code used to generate the parameters of Table 1 and the test results in Supplementary Tables S1-S5 are available from the corresponding author upon request.

\section{References only in Methods}

28 Klimont, Z., Smith, S. J. \& Cofala, J. The last decade of global anthropogenic sulfur dioxide: 2000-2011 emissions. Environ Res Lett 8, doi:Artn 014003, Doi 10.1088/17489326/8/1/014003 (2013).

29 Smith, S. J. et al. Anthropogenic sulfur dioxide emissions: 1850-2005. Atmos Chem Phys 11, 1101-1116, doi:Doi 10.5194/Acp-11-1101-2011 (2011).

30 Magnus, J. R., Melenberg, B. \& Muris, C. Global Warming and Local Dimming: The Statistical Evidence. J Am Stat Assoc 106, 452-464, doi:Doi 10.1198/Jasa.2011.Ap09508 (2011). 


\section{Online-only Methods}

The panel model for local temperature evolution given in Equations 2 and 3 is formulated in the predictive regression format ${ }^{31}$, where the time specific variate $\lambda_{t}$ captures common global temperature, radiation, and greenhouse gas influences on station specific temperature. These global variables typically manifest evidence of stochastic trend (or autoregressive unit root ${ }^{32}$ ) behavior over time, as is known from earlier climate research ${ }^{17,33,34}$. The data used in the present study were tested for evidence of unit roots using augmented Dickey Fuller (ADF) ${ }^{35}$, PhillipsPerron (PP) ${ }^{32,36}$ and $\mathrm{KPSS}^{37}$ tests. The results (which are shown in Table S1 of the Supplementary Information) are confirmatory of the presence of stochastic trends for all variables, although for variable $T$ the ADF and PP coefficient test results are sensitive to the inclusion of deterministic trends in the regression, favoring trend stationarity in that case. The spatial panel formulation (Equations 2 and 3) allows for local site dynamic responses (via $\left.\beta_{1} T_{i, t}\right)$ to local radiation effects $\left(R_{i, t}\right)$ while controlling for the time series impact of global climate indicators and forcing agents through the presence of $\lambda_{t}$. Time series nonstationarity, as well as potential cointegration among these global variables, is accommodated by the predictive regression form of the formulation.

When $T_{t}, R_{t}$, and $\mathrm{CO}_{2, e q}$ are cointegrated, the time specific effect $\lambda_{t}$ may be interpreted as a long run equilibrium global forcing effect that acts as one of the drivers of the local temperature dynamics in Equation 2. This equation then falls within the (spatial panel) framework of error correction mechanisms in econometrics ${ }^{38}$. The site specific innovations $u_{i, t+1}$ are assumed to be martingale differences with respect to past information and aggregate shocks. (In effect, site- 
specific individual innovations at time $t+1$ are uncorrelated with aggregate shocks and radiation effects that have occurred up to time t). Since estimation and inference involves spatial averaging as well as temporal averaging, the asymptotic theory is normal and inference is standard for the parameters in Equation $2^{39}$. This conclusion holds even when the global variables are themselves cointegrated rather than full rank nonstationary.

Cointegration tests among the global variables were conducted and these are reported in Supplementary Table S2. The residual based tests used here are the Phillips and Ouliaris ${ }^{40}$ coefficient ( $\mathrm{z}$ ) and t-ratio ADF $(\tau)$ tests for the presence of unit roots in the residuals from cointegrating regressions among the global variables (details are provided in Table S2). Critical values are obtained from MacKinnon ${ }^{41}$. The test results show strong evidence of cointegration among the global variables and these results are robust to the presence of a deterministic trend in the cointegrating regression. There is also evidence of dyadic cointegration in the pairs $\left(T_{t}, R_{t}\right)$ and $\left(T_{t}, C_{2, e q}\right)$, the latter corroborating evidence in earlier work ${ }^{33,34,42}$.

We considered two extensions that involve model formulation and estimation. First, Equations 2 and 3 were formulated to allow for latitudinal coefficient variation. We analyzed the impact of latitude on the parameter estimates by parameterizing according to four spatial regions: the southern hemisphere $\left(\mathrm{SH}, 90^{\circ} \mathrm{S}-15^{\circ} \mathrm{S}\right)$, the tropics $\left(\operatorname{Tr}, 15^{\circ} \mathrm{S}-15^{\circ} \mathrm{N}\right)$, the northern hemisphere subtropics (NHs, $15^{\circ} \mathrm{N}-45^{\circ} \mathrm{N}$ ), and the northern hemisphere high latitudes (NHh, $45^{\circ} \mathrm{N}-90^{\circ} \mathrm{N}$ ). The observations from surface stations in these separate regions are then used to estimate the region-specific parameters. Note that Equations 2 and 3 are based on global energy balance considerations, and thus the outcome of applying the same equations to separate regions, albeit 
large, must be interpreted with that in mind. The results are reported in Supplementary Table S3. The main features to emerge from these findings are as follows:

(i) A larger sensitivity to $\mathrm{CO}_{2}$ at high latitudes than in the tropics, with the northern hemisphere (NH) mid-latitudes yielding the largest $\gamma_{3}$ values. This is consistent with the well-known and expected polar amplification of $\mathrm{CO}_{2}$ warming.

(ii) Remarkably consistent parameter values across latitude bands, with local radiation effects generally being statistically significant, in contrast with the global radiation effect.

(iii) In the tropics and southern hemisphere (SH), a global radiation effect similar in magnitude, but of opposite sign, compared to the local radiation effect. This is suggestive of a significant contribution to dimming from black carbon (BC) in this region, which is consistent with the large BC sources from biomass burning in the tropics and $\mathrm{SH}$. In the NH, there is no such cancellation, suggesting that cooling aerosols like sulfate dominate the radiation trends there. This is again consistent with global climate modeling and satellite observations.

(iv) NH sub-tropics and mid-latitudes (15-45 degrees $\mathrm{N}$ ) show the highest sensitivity to trends in DSRS. This is consistent with the findings of ref. 20. The rationale is that $\mathrm{NH}$ mid-latitudes have the most land coverage (see Fig. 1b), so the DSRS triggers more rapid land responses and climate feedback mechanisms there than elsewhere.

(v) Parameter $\gamma_{1}$ is negative everywhere, indicative of the dominant influence of the Planck feedback on this parameter. However, $\gamma_{1}$ is less negative in the $\mathrm{NH}$ than in the tropics and $\mathrm{SH}$ sub-tropics (though their confidence intervals overlap), possibly suggesting that increased heat transport from the SH and tropics into the NH extra-tropics may compensate for some of the additional heat lost to space through infrared radiation as the $\mathrm{NH}$ surface warms. This would be consistent with the observation of a southward shift in the Intertropical Convergence Zone 
(ITCZ) during the second half of the 20th century, and an associated increased energy flux from the southern to the northern hemisphere ${ }^{43}$. The ITCZ shift has been attributed to the hemispherically asymmetric cooling effect from anthropogenic aerosols.

The second extension involves the method of estimation. In view of the stochastic trends in the global variables $\left(T_{t}, R_{t}, C O_{2, e q, t}\right)$, the system was re-estimated using dynamic ordinary least squares (DOLS) $)^{44-46}$. This technique includes lead and lag differences in the regression and, as explained in the cited works, provides a convenient linear regression approach for dealing with any error correlation contamination and bias that might arise in nonstationary cointegrating regression. The technique has been used in earlier work by Kaufmann et al. ${ }^{34}$. This modification leads to the following reformulation of Equations 2 and 3 as

$$
\begin{aligned}
& T_{i, t+1}=\beta_{0}+\beta_{1} \cdot T_{i, t}+\beta_{2} \cdot R_{i, t}+\lambda_{t}+u_{i, t+1} \\
& \lambda_{t}=\gamma_{0}+\gamma_{1} \cdot T_{t}+\gamma_{2} \cdot R_{t}+\gamma_{3} \cdot \ln \left(C O_{2, e q, t}\right)+\gamma_{b} \cdot \Delta X_{t-1}+\gamma_{c} \cdot \Delta X_{t+1}
\end{aligned}
$$

where $X=\left[R, \ln \left(\mathrm{CO}_{2, e q}\right)\right]$ with corresponding coefficient vectors $\gamma_{b}=\left[\gamma_{2, b}, \gamma_{3, b}\right], \gamma_{c}=$ $\left[\gamma_{2, c}, \gamma_{3, c}\right]$. In this system, as noted above, the time specific effect $\lambda_{t}$ serves as a long run equilibrium error in the global energy balance, an interpretation that is confirmed by unit root tests which strongly reject the presence of a stochastic trend in $\lambda_{t}$ (see Supplementary Table S4) and corroborate the finding of cointegration among the trending variables $\left(T_{t}, R_{t}, C O_{2, e q, t}\right)$. Note that Equation 4 is formulated with lead differences $\Delta X_{t+1}$ and lagged differences $\Delta X_{t-1}$ in the primary driver variables $X_{t}$, just as in the usual formulation of a DOLS cointegrating regression of $T_{t}$ on $X_{t}$. Equation 4 then falls within the well-studied framework of an error correction 
mechanism in econometrics ${ }^{38}$, although its significance in the present spatial-panel context emerges from the role that the global forcing variables $X_{t}$ and temperature $T_{t}$ play in the determination of site specific dynamics of $T_{i, t+1}$ in Equation 4.

The parameter estimates obtained from DOLS regression are given in Supplementary Table S5. The estimates of the global level variable coefficients $\left(\gamma_{1}, \gamma_{2}, \gamma_{3}\right)$ and the associated confidence intervals are in each case close to those reported in Table 1. The findings therefore corroborate those from the direct panel regression given without the inclusion of lead and lagged differences, showing that the results are robust to the use of cointegrating methods that allow for the presence of stochastic trends in the data.

\section{References in Online-only Methods:}

31 Phillips, P. C. B. Halbert White Jr. Memorial JFEC Lecture: Pitfalls and Possibilities in Predictive Regression. J Financ Economet 13, 521-555, doi:10.1093/jjfinec/nbv014 (2015).

32 Phillips, P. C. B. Time-Series Regression with a Unit-Root. Econometrica 55, 277-301, doi:Doi 10.2307/1913237 (1987).

33 Kaufmann, R. K., Kauppi, H. \& Stock, J. H. Emissions, concentrations, \& temperature: A time series analysis. Climatic Change 77, 249-278, doi:10.1007/s10584-006-9062-1 (2006).

34 Kaufmann, R. K., Kauppi, H. \& Stock, J. H. The relationship between radiative forcing and temperature: What do statistical analyses of the instrumental temperature record measure? Climatic Change 77, 279-289, doi:10.1007/s10584-006-9063-0 (2006).

35 Said, S. E. \& Dickey, D. A. Testing for Unit Roots in Autoregressive-Moving Average Models of Unknown Order. Biometrika 71, 599-607 (1984).

36 Phillips, P. C. B. \& Perron, P. Testing for a Unit-Root in Time-Series Regression. Biometrika 75, 335-346, doi:DOI 10.1093/biomet/75.2.335 (1988).

37 Kwiatkowski, D., Phillips, P. C. B. \& Schmidt, P. Testing for Stationarity in the Components Representation of a Time-Series. Economet Theor 8, 586-591 (1992).

38 Engle, R. F. \& Granger, C. W. J. Cointegration and Error Correction - Representation, Estimation, and Testing. Econometrica 55, 251-276, doi:Doi 10.2307/1913236 (1987).

39 Phillips, P. C. B. \& Moon, H. R. Linear regression limit theory for nonstationary panel data. Econometrica 67, 1057-1111, doi:Doi 10.1111/1468-0262.00070 (1999).

40 Phillips, P. C. B. \& Ouliaris, S. Asymptotic Properties of Residual Based Tests for Cointegration. Econometrica 58, 165-193, doi:Doi 10.2307/2938339 (1990). 
41 Mackinnon, J. G. Approximate Asymptotic-Distribution Functions for Unit-Root and Cointegration Tests. J Bus Econ Stat 12, 167-176, doi:Doi 10.2307/1391481 (1994).

42 Kaufmann, R. K., Kauppi, H., Mann, M. L. \& Stock, J. H. Does temperature contain a stochastic trend: linking statistical results to physical mechanisms. Climatic Change 118, 729-743, doi:10.1007/s10584-012-0683-2 (2013).

43 Schneider, T., Bischoff, T. \& Haug, G. H. Migrations and dynamics of the intertropical convergence zone. Nature 513, 45-53, doi:10.1038/nature13636 (2014).

44 Phillips, P. C. B. \& Loretan, M. Estimating Long-Run Economic Equilibria. Rev Econ Stud 58, 407-436, doi:Doi 10.2307/2298004 (1991).

45 Saikkonen, P. Asymptotically Efficient Estimation of Cointegration Regressions. Economet Theor 7, 1-21 (1991).

46 Stock, J. H. \& Watson, M. W. A Simple Estimator of Cointegrating Vectors in HigherOrder Integrated Systems. Econometrica 61, 783-820, doi:Doi 10.2307/2951763 (1993). 
Table 1: Parameter values, standard errors and confidence intervals for the parameters of Equations 2 and 3. Green shading indicates statistical significance, red shading shows lack thereof.

\begin{tabular}{|l|l|l|l|c|}
\hline Parameter & Value & $\begin{array}{l}\text { Std. } \\
\text { Error }\end{array}$ & $\begin{array}{l}\text { 95\% confidence } \\
\text { interval }\end{array}$ & $\begin{array}{l}\text { Relevant } \\
\text { variable }\end{array}$ \\
\hline $\boldsymbol{\beta}_{1}$ & 0.9212 & 0.0040 & $(0.9133,0.9292)$ & $T_{i}$ \\
\hline $\boldsymbol{\beta}_{2}$ & 0.0127 & 0.0006 & $(0.0108,0.0146)$ & $R_{i}$ \\
\hline $\boldsymbol{\Upsilon}_{\boldsymbol{1}}$ & -0.8438 & 0.1573 & $(-1.1611,-0.5266)$ & $T$ \\
\hline $\boldsymbol{\Upsilon}_{2}$ & 0.0025 & 0.0089 & $(-0.0154,0.0205)$ & $R$ \\
\hline $\boldsymbol{\Upsilon}_{3}$ & 4.4056 & 0.9892 & $(2.4107,6.4005)$ & $\mathrm{CO}_{2, \text { eq }}$ \\
\hline
\end{tabular}


